\title{
Polarimetric SAR interferometry applied to land ice: first results
}

\author{
Dall, Jørgen; Papathanassiou, K.P.; Skriver, Henning
}

Published in:

Proceedings of the IEEE 2003 International Geoscience and Remote Sensing Symposium (IGARSS)

Publication date:

2003

Document Version

Publisher's PDF, also known as Version of record

Link back to DTU Orbit

Citation (APA):

Dall, J., Papathanassiou, K. P., \& Skriver, H. (2003). Polarimetric SAR interferometry applied to land ice: first results. In Proceedings of the IEEE 2003 International Geoscience and Remote Sensing Symposium (IGARSS) (Vol. 3, pp. 1432-1434). IEEE.

\section{General rights}

Copyright and moral rights for the publications made accessible in the public portal are retained by the authors and/or other copyright owners and it is a condition of accessing publications that users recognise and abide by the legal requirements associated with these rights.

- Users may download and print one copy of any publication from the public portal for the purpose of private study or research.

- You may not further distribute the material or use it for any profit-making activity or commercial gain

- You may freely distribute the URL identifying the publication in the public portal

If you believe that this document breaches copyright please contact us providing details, and we will remove access to the work immediately and investigate your claim. 


\title{
POLARIMETRIC SAR INTERFEROMETRY APPLIED TO LAND ICE: FIRST RESULTS
}

\author{
J. Dall ${ }^{1}$, K.P. Papathanassiou ${ }^{2}$, and H. Skriver ${ }^{1}$ \\ 1: Electromagnetic Systems, Ørsted $\bullet$ DTU, Technical University of Denmark \\ Ørsteds Plads 348, DK-2800 Kongens Lyngby, Denmark \\ Tel: +45 4525 3800, Fax: +45 4593 1634, E-mail: jd@oersted.dtu.dk \\ 2: German Aerospace Center (DLR) \\ D-82230 Oberpfaffenhoven, Germany \\ Tel/Fax: +49 815328 2367/1449, E-mail: kostas.papathanassiou@dlr.de
}

\begin{abstract}
This paper presents first results obtained from the analysis of fully polarimetric / interferometric land ice data. It is demonstrated that L-band data from an ice cap located in the percolation zone of Greenland show a strong polarization dependent interferometric behavior. No model-based inversion has yet been attempted, but a radar reflector deployed on the ice surface suggests an effective penetration depth of about $15 \mathrm{~m}$.
\end{abstract}

\section{INTRODUCTION}

Monitoring polar ice sheets and temperate glaciers is an important element in understanding global change. Radar techniques already play an important role in this monitoring and polarimetric SAR interferometry (Pol-InSAR) is expected to add new and refined capabilities.

No results have been published on glaciological applications of Pol-InSAR, which has so far mainly been used to estimate forest parameters like tree height [1]. The success of Pol-InSAR techniques in forest vegetation studies is due to its ability to extract geophysical parameters from volumes with a vertical distribution of scattering mechanisms or/and with polarization dependent propagation characteristics. Land ice is another important natural volume scatterer for which PolInSAR may enable quantitative parameter inversion.

From field measurements it is known that land ice is very diverse and complex. This has subsequently been confirmed by polarimetric SAR measurements [2]. The ice sheet of Greenland is composed of four ice zones ranging from the ablation zone at low elevations, over the wet-snow zone and the percolation zone to the dry-snow zone at the highest elevations. Most of Antarctica is in the dry-snow zone, while temperate glaciers only have ablation and wet-snow zones.

In the percolation zone the firn is basically dry and hence fairly transparent to microwaves. In summer, melt water from the surface percolates to more impermeable layers, where it may spread out laterally, refreeze in the cold snow, and form ice lenses. Upon refreezing the vertical percolation channels form structures called ice pipes. These ice inclusions are known to cause a high radar backscatter with large polarization ratios [2].

The land ice parameters that can potentially be estimated with Pol-InSAR are true surface elevation (without penetra- tion bias), penetration depth, ice parameters (water contents, grain size, density of ice inclusions) and surface roughness.

With a potential of providing digital elevation models (DEMs) corrected for penetration bias, Pol-InSAR is an interesting supplement to radar altimetry, especially in the marginal ice zone, where radar altimetry fails due to the surface slopes / undulations. Also, Pol-InSAR might support climate studies by facilitating classification of ice zones.

\section{DATA}

Pol-InSAR data suitable for land ice applications are scarce. However, L-band repeat-pass Pol-InSAR data from the Geikie ice cap in East Greenland were acquired by EMISAR [3] in August 1998. The flight altitude above the ice surface was $7.6 \mathrm{~km}$ and the orthogonal baseline was about $30 \mathrm{~m}$ corresponding to an ambiguous height of $20 \mathrm{~m}$ in near range and $60 \mathrm{~m}$ in far range. Supplementary data were also acquired, e.g., snow accumulation rate and ice velocity. Finally, a shallow ice core was drilled and analyzed to obtain a profile of ice temperature, density, and ice inclusions [4].

Prior to the flight, trihedral radar reflectors had been deployed on the ice surface and surveyed with GPS. The reflectors serve as calibration devices for SAR DEMs and they enable the penetration depth at each reflector to be estimated directly from the SAR DEM as the difference between the height of the reflector and the height of the surrounding ice.

In 1997, EMISAR acquired C-band single-pass interferometric SAR data from Geikie and a profiling laser altimeter was flown. By comparison of calibrated DEMs from these two instruments, penetration depths up to $13 \mathrm{~m}$ were measured and verified with the reflectors [5].

\section{ANALYSIS}

The coherent scattering vector in the $H V$-polarimetric basis is [6]

$$
\begin{aligned}
& \mathbf{k}=\frac{1}{\sqrt{2}}\left[S_{H H}+S_{V V}, S_{H H}-S_{V V}, S_{X P}\right]^{T} \\
& S_{X P}=S_{H V}+S_{V H}
\end{aligned}
$$




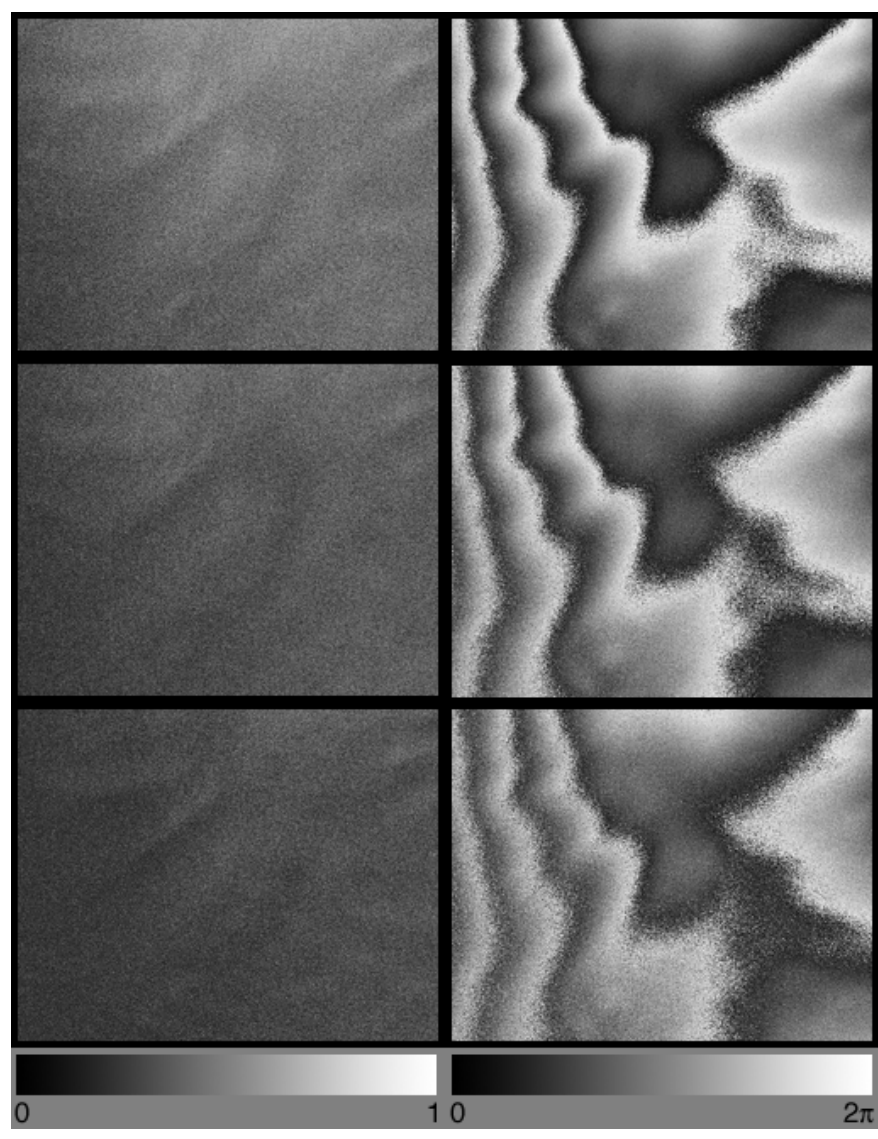

Fig. 1. Amplitude (left) and phase (right) of the coherence for three distinct scattering mechanisms: $H H-H H, V V-V V, X P-X P$ (from top).

where $T$ means matrix transpose and $S_{r t}$ is the complex scattering coefficient for $t$ transmitted and $r$ received polarization $(r, t=H$ or $V)$. A scattering coefficient can be defined by projecting $\mathbf{k}$ onto a normalized complex vector $\mathbf{w}$ [6]

$$
\mu=\mathbf{w}^{*} T \mathbf{k}
$$

Here the asterisk means complex conjugation. For a pair of scattering vectors $\left(\mathbf{k}_{1}, \mathbf{k}_{2}\right)$ and an arbitrary pair of scattering mechanisms $\left(\mathbf{w}_{1}, \mathbf{w}_{2}\right)$ the complex interferometric coherence is [6].

$$
\gamma\left(\mathbf{w}_{1}, \mathbf{w}_{2}\right)=\frac{\left\langle\mu_{1} \mu_{2}^{*}\right\rangle}{\sqrt{\left\langle\mu_{1} \mu_{1}^{*}\right\rangle\left\langle\mu_{2} \mu_{2}^{*}\right\rangle}}
$$

Fig. 1 shows the coherence for linear polarization. The $\mathrm{HH}$ $H H$ and $X P-X P$ interferograms have the smallest and the largest phase noise respectively. For the optimum scattering mechanisms [6] Fig. 2 shows the amplitudes of the coherence and the scattering coefficient $\mu_{2}$. The large variation of the interferometric coherence with polarization indicates a strong polarization dependency of the vertical distribution of effective scattering mechanisms or/and of the propagation through the ice volume.

In Fig. 3 the loci of the mean coherences are plotted on the unit circle [1]. In this representation the variation of the co-

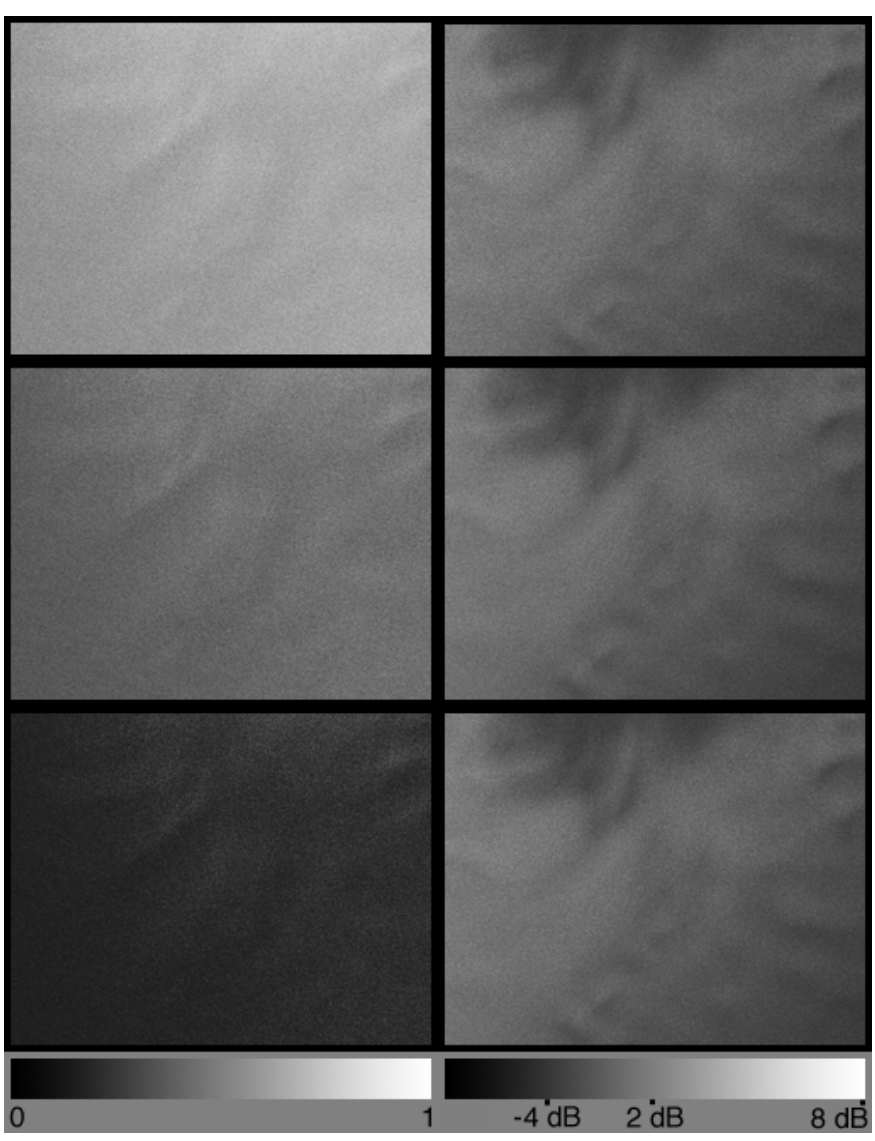

Fig. 2. Optimization: coherence amplitude (left) and scattering coefficient amplitude (right). A linear scale is used.

herence values, even within the conventional $H V$ polarimetric basis, becomes evident, though barely detectable in Fig 1 . The phase variation of the linear polarizations in Fig. 3 is consistent with the change of fringe patterns in Fig. 1.

While the coherences for the circular scattering mechanisms $(R R-R R, L L-L L$ and $R L-R L)$ are in line with the linear ones the three optimum coherences deviate. The deviation reduces when a higher degree of averaging is used for the coherence computation. The reason for this may lie in the fairly inhomogeneous nature of land ice with few dominant scatters present in each resolution cell [2].

In Fig. 3, the optimum coherences have significantly different amplitudes but not much phase variation. This combination is characteristic to surface scattering with a low signal-tonoise ratio (SNR), but since the amplitude of the scattering coefficient in Fig. 2 (right) is almost independent of the scattering mechanism, SNR is not an issue in this case.

The trihedral in Fig. 4 has a low $X P$ - $X P$ coherence because, ideally, the trihedral is invisible at $X P$ polarization. The fact that the $H H-H H$ and $V V-V V$ phases are quite close confirms that the variation of the coherence phase in Fig. 1 and 3 is actually due to a polarization dependent interferometric behavior of the ice and not due to an artifact. A common polarimetric phase imbalance would cancel in (3) when $\mathbf{w}_{1}=\mathbf{w}_{2}$, but if data set 1 and 2 had different phase imbalances, the coherence would be subject to a phase artifact. 


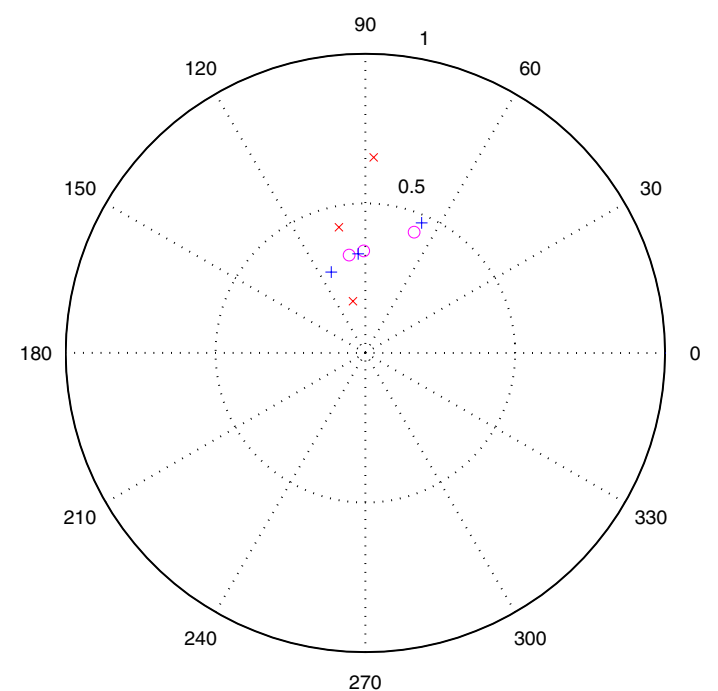

Fig. 3. Mean coherence for linear $(+)$, circular (o), and optimum $(\times)$ scattering mechanisms.

\section{INVERSION}

The geophysical interpretation of the experimental observations is still ongoing, but it can already be concluded that land ice is characterized by a strong polarization dependent interferometric behavior. This statement is based on the fact that the coherence amplitude and phase vary with the scattering mechanism.

Although any retrieval of geophysical parameters like true surface elevation and penetration depth is still premature it is worth noting that the coherence points for linear and circular scattering mechanisms appear to be located on a straight line in the unit circle in Fig. 3. A straight line results from the random-volume-over-ground model [7] frequently used in relation to forest vegetation studies [1]. More interestingly, it also results from an equivalent random-volume-under-surface model, which could possibly be relevant to the ice scenario. However, the presence of orientation effects within the ice volume cannot be excluded based on the observations up to now. Orientation effects leading to polarimetric propagation effects are not unlikely in view of the inclusion of vertical ice pipes and horizontal ice layers and lenses in the percolation facies.

The trihedral offers a means of estimating the effective penetration depth directly. The phase difference between corresponding reflector and ice points in Fig. 4 ranges from $83^{\circ}$ to $96^{\circ}$, which for the mapping geometry and system parameters in question, translate into elevation differences between $13 \mathrm{~m}$ and $15 \mathrm{~m}$. For comparison, $10 \mathrm{~m}$ was measured at C-band the previous year [5].

It is noted that if a straight line is fitted to the ice points in Fig. 4, this line does not point towards the co-polar trihedral points as suggested by a potential random-volume-undersurface model.

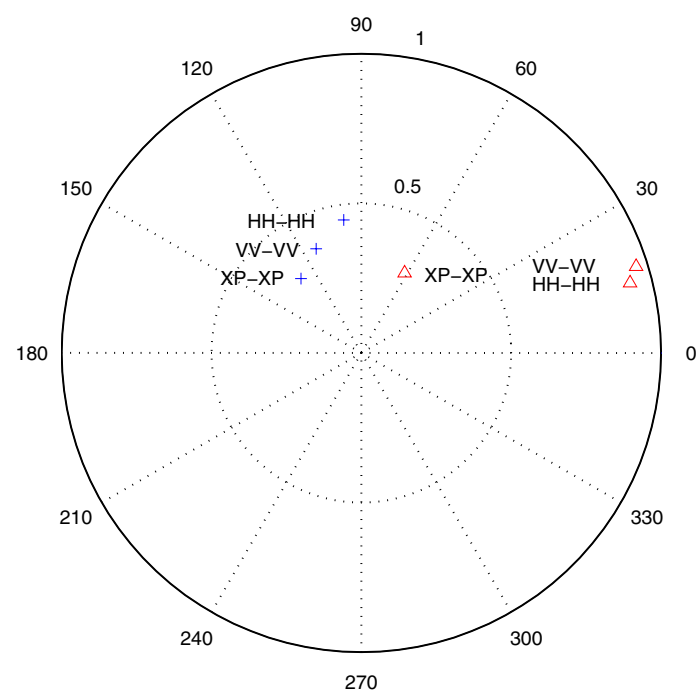

Fig. 4. Coherence at linear polarization for trihedral $(\Delta)$ and for surrounding ice $(+)$ (mean value).

\section{SUMMARY}

For the first time, the Pol-InSAR technique has been applied to land ice. It has been demonstrated that L-band EMISAR data acquired over an ice cap located in the percolation zone of Greenland exhibit a polarimetric interferometric effect in the sense that the amplitude and phase of the complex coherence depend on the scattering mechanism.

Geophysical modeling and interpretation is still ongoing, but by using a trihedral deployed on the ice surface, a first estimate of the effective penetration depth at L-band has been obtained.

\section{REFERENCES}

[1] K.P. Papathanassiou and S.R. Cloude, "Single-Baseline Polarimetric SAR interferometry", IEEE Transactions on Geoscience and Remote Sensing, vol. 39, no. 11, pp. 2352-2363, 2001.

[2] E. Rignot, "Backscatter Model for the Unusual Radar Properties of the Greenland Ice Sheet", Journal of Geophysical Research, vol. 100, no. E5, pp. 9389-9400, 1995.

[3] E. Lintz Christensen, N. Skou, J. Dall, K.W. Woelders, J.H. Jørgensen, J. Granholm, S.N. Madsen, "EMISAR: An Absolutely Calibrated Polarimetric L- and C-band SAR", IEEE Transactions on Geoscience and Remote Sensing, vol. 36, no. 6, pp. 1852-1865, 1998.

[4] C.S. Nielsen, "Topography and Surface velocities of an Irregular Ice Cap in Greenland Assessed by means of GPS, Laser Altimetry and SAR interferometry", Ph.D. thesis, 81 pp., University of Copenhagen, Dept. of Geophysics, January 2000.

[5] J. Dall, S.N. Madsen, K. Keller, R. Forsberg, "Topography and Penetration of the Greenland Ice Sheet Measured with Airborne SAR Interferometry", Geophysical Research Letters, Vol. 28, No 9, pp. 1703-1706, 2001.

[6] S.R. Cloude, K.P. Papathanassiou, "Polarimetric SAR Interferometry", IEEE Transactions on Geoscience and Remote Sensing, vol. 36, no. 5, pp. 1551-1565, 1998.

[7] R.N. Treuhaft and P.R. Siqueira, "Vertical Structure of Vegetated Land Surfaces from Interferometric and Polarimetric Radar", Radio Science, vol. 35, pp. 141-177, 2000. 